\title{
Combined Effects of Viscous Dissipation and Thermal Radiation on non-Newtonian Fluid Along a Surface with Heat Generation and Uniform Surface Heat Flux
}

\author{
D. R. Pal and M. A. Samad \\ Department of Applied Mathematics, Dhaka University, Dhaka-1000, Bangladesh
}

(Received: 23 October 2014; Accepted: 16 March 2015)

\begin{abstract}
The paper analyses the effects of Magneto-hydrodynamic (MHD) free convective heat and mass transfer flow on non-Newtonian power law fluids along a continuously moving stretching sheet with radiation, heat generation and viscous dissipation under the simultaneous action of suction, thermal radiation, heat source, uniform transverse magnetic field and viscous dissipation. The governing non-linear partial differential equations describing the flow fields under consideration are transformed into non-linear ordinary differential equations by using appropriate analysis of similarity and then solved the resulting problem numerically by applying Nachtsheim-Swigert shooting iterative technique along with sixth order Runge-Kutta integration scheme. The computational results of the skin friction coefficient $\left(C_{f}\right)$, the rate of heat transfer namely the local Nusselt number $\left(N u_{x}\right)$ and the mass transfer coefficient namely the local Sherwood number $\left(S h_{x}\right)$ have also been presented in tabular form. In the present study, a comparison has also been done with a published article and found a good agreement.
\end{abstract}

Keywords: Non-Newtonian Power-Law Fluid, Stretching Sheet, Thermal Radiation, Heat Generation, Surface Heat Flux, Viscous Dissipation.

\section{Introduction}

Our contemporary life is highly influenced by modern technology and industrial applications, particularly use of non-Newtonian fluids. Many polymer solutions and molten polymers are non-Newtonian fluids, as are many commonly found substances such as ketchup, custard, toothpaste, starch suspensions, paint, blood, and shampoo. Non-Newtonian fluids are important because its viscosity changes when the gradient in flow speed changes. But there are some difficulties such as exact solutions of the equations of motion of non- Newtonian fluids are difficult to obtain. The difficulty arises not only due to the non-linearity but also due to increase in the order of differential equations. The study of free convective and heat transfer flows for non-Newtonian fluid along a stretching sheet has been attracted by many engineers and researchers because of their possible applications in many branches of science and technology. Sakiadis ${ }^{1}$ was the first to investigate the flow due to sheet issuing with constant speed from a slit into a fluid at rest. Schowalter ${ }^{2}$ has introduced the concept of the boundary layer in the theory of non-Newtonian power-law fluids. Elbashbeshy ${ }^{3}$ examined the effects of injection and suction on the heat transfer from a stretching surface with variable surface heat flux. The interest in MHD fluid flows arise from the fact that liquid metals which occur in nature and industry are electrically conducting has been dealt with by several authors Andersson et al. ${ }^{4}$, Cortell ${ }^{5}$ and Mahmoud and Mahmoud $^{6}$. B. Singh and C.Thakur ${ }^{7}$ studied the unsteady two dimensional, second grade, electrically conducting MHD non-Newtonian fluid flows.Chiam ${ }^{8}$ studied the boundary layer flow of a Newtonian fluid over a stretching plate in the presence of a transverse magnetic field. Kishan and B.S. Reddy ${ }^{9}$ studied the MHD effects on boundary layer flow of power-law fluids past a semi infinite flat plate with thermal dispersion. K. Vajravelu and A. Hadjiricaloou ${ }^{10}$ studied over convective heat transfer in an electrically conducting fluid at a stretching surface. Rajgopal et al. ${ }^{11}$ studied flow of viscoelastic fluid over a stretching sheet. Gupta et al. ${ }^{12}$ extended the problem to study of heat transfer, and Datti et al. ${ }^{13}$ analysed the problem over a non-isothermal stretching sheet. M.A. Samad and M. Mohebujjaman ${ }^{14}$ analysed MHD heat and mass transfer free convection flow. The MHD convective flow of a micropolar fluid past a continuously moving vertical porous plate in the presence of heat generation/absorption was studied by Rahman and Sattar $^{15}$ and Raptis ${ }^{16}$. Recently, Chien-Hsin Chen ${ }^{17}$ has studied the magneto-hydrodynamic flow and heat transfer of an electrically conducting, non-Newtonian power-law fluid past a stretching sheet in the presence of a transverse magnetic field by considering suction/injection.

In recent years, the radiation effect on MHD free convective flow and heat transfer problems has become more important industrially. Many processes of industrial areas occur at high temperatures and the knowledge of radiative heat transfer becomes very important for the design of the equipments. Nuclear power plants, gas turbines and the various propulsion devices for aircrafts etc. are example of such engineering areas. Nachtsheim and swigert ${ }^{18}$ worked on the numerical solution of the system of nonlinear equations of boundary condition. Tania S. Khaleque and M.A. Samad ${ }^{19}$ extended the study of the effects of radiation, heat generation and viscous dissipation.

In the present work, the effect of viscous dissipation and thermal radiation on non-Newtonian power-law fluids along a continuously moving stretching surface with heat generation and uniform surface heat flux have been investigated. The present study is more generalized from the previous work performed by $\mathrm{Chen}^{17}$. The effects of free convection, heat generation and radiation have been accomplished which were not considered in the work of Chen $^{17}$. A comparison of the present study have been done with Chen ${ }^{17}$ and found a good agreement.

\section{Governing Equations}

Let us consider a steady two dimensional MHD free convective laminar boundary layer flow of a non-Newtonian power-law and electrically conducting fluid along a continuously moving stretching sheet in the presence of heat 
generation under the influence of thermal radiation, heat generation and viscous dissipation.

The $\mathrm{X}$-axis is taken along the stretching sheet in the vertically upward direction and the Y-axis is taken normal to the sheet. Two equal and opposite forces are introduced along the $\mathrm{X}$ axis, so that the sheet is stretched.

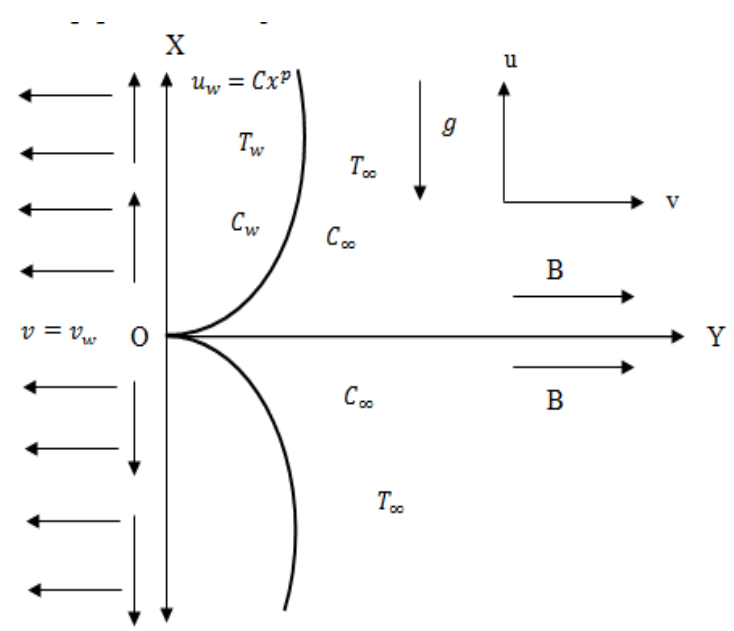

Fig.1. Flow structure of the boundary layer

The fluid is considered to be gray, absorbing-emitting radiation but non-scattering medium and the Rossland approximation is used to describe the radioactive heat flux in the energy equation. The concentration is assumed to be nonreactive.

This continuous sheet is assumed to move with a velocity according to a power law form, i.e. $\mathrm{u}_{\mathrm{w}}=\mathrm{Cx}^{\mathrm{p}}$ and be subject to a surface heat. The ambient temperature of the flow is $\mathrm{T}_{\infty}$ and the concentration of the uniform flow is $\mathrm{C}_{\infty}$.

Hence, only the applied magnetic field B plays a role which gives rise to magnetic forces $\mathrm{F}_{\mathrm{x}}=\frac{\sigma \mathrm{Bu}}{\rho}$ in the $\mathrm{X}$-direction, where $\sigma$ is the electrical conductivity, $\mathrm{B}$ is the magnetic field strength and $\rho$ is the density of the fluid. Under the above assumptions, the governing boundary layer equations are:

$$
\begin{aligned}
& \frac{\partial u}{\partial x}+\frac{\partial v}{\partial y}=0 \\
& u \frac{\partial u}{\partial x}+v \frac{\partial u}{\partial y}=\frac{K}{\rho} \frac{\partial}{\partial y}\left(\left|\frac{\partial u}{\partial y}\right|^{n-1} \frac{\partial u}{\partial y}\right)+s g \beta\left(T-T_{\infty}\right)-\frac{\sigma B^{2} u}{\rho} \\
& u \frac{\partial T}{\partial x}+v \frac{\partial T}{\partial y}=\alpha \frac{\partial^{2} T}{\partial y^{2}}+\frac{Q_{0}}{\rho C_{p}}\left(T-T_{\infty}\right)-\frac{1}{\rho C_{p}} \frac{\partial q_{r}}{\partial y}+ \\
& \frac{K}{\rho C_{p}}\left(\left|\frac{\partial u}{\partial y}\right|^{n-1} \frac{\partial u}{\partial y}\right)^{2} \\
& u \frac{\partial c}{\partial x}+v \frac{\partial c}{\partial y}=D_{m} \frac{\partial^{2} c}{\partial y^{2}}
\end{aligned}
$$

where, $K$ is the consistency coefficient, $c_{p}$ is the specific heat at constant pressure, $T$ is the temperature of the fluid layer, $g$ is the acceleration due to gravity, $\beta$ is the volumetric coefficient of thermal expansion, $\alpha=\frac{\kappa}{\rho c_{p}}$ is the thermal diffusivity, $\kappa$ is the thermal conductivity of the fluid, $n$ is the flow behavior index, $q_{r}$ is the radiative heat flux, $\mathrm{C}$ is the concentration of the fluid within the boundary layer and $D_{m}$ is the mass diffusivity.

The radiative heat flux $q_{r}$ is described by Rossland approximation such that,

$q_{r}=-\frac{4 \sigma_{1}}{3 \kappa_{1}} \frac{\partial T^{4}}{\partial y}$

where $\sigma_{1}$ is the Stefan-Boltzman constant and $\kappa_{1}$ is the Rossland mean absorption coefficient. It is assumed that the temperature differences within the flow are sufficiently small such that $T^{4}$ can be expressed in a Taylor series about the free stream temperature $T_{\infty}$ and then neglecting higherorder terms resulting in the following approximation:

$T^{4} \approx 4 T_{\infty}^{3}-3 T_{\infty}^{4}$

Using equation (5) and (6) in the last term of equation (3), we obtain,

$\frac{\partial q_{r}}{\partial y}=-\frac{16 \sigma_{1} T_{\infty}^{3}}{3 \kappa_{1}} \frac{\partial^{2} T}{\partial y^{2}}$

Introducing $q_{r}$ in equation (3), we obtain the following governing boundary layer equations:

$\frac{\partial u}{\partial x}+\frac{\partial v}{\partial y}=0$

$u \frac{\partial u}{\partial x}+v \frac{\partial u}{\partial y}=\frac{K}{\rho} \frac{\partial}{\partial y}\left(\left|\frac{\partial u}{\partial y}\right|^{n-1} \frac{\partial u}{\partial y}\right)+$

$\operatorname{sg} \beta\left(T-T_{\infty}\right)-\frac{\sigma B^{2} u}{\rho}$

$\frac{\partial T}{\partial x}+v \frac{\partial T}{\partial y}=\alpha \frac{\partial^{2} T}{\partial y^{2}}+\frac{Q_{0}}{\rho C_{p}}\left(T-T_{\infty}\right)+\frac{1}{\rho C_{p}} \frac{16 \sigma_{1} T_{\infty}^{3}}{3 \kappa_{1}} \frac{\partial^{2} T}{\partial y^{2}}+$

$\frac{K}{\rho c_{p}}\left(\left|\frac{\partial u}{\partial y}\right|^{n-1} \frac{\partial u}{\partial y}\right)^{2}$

$u \frac{\partial c}{\partial x}+v \frac{\partial c}{\partial y}=D_{m} \frac{\partial^{2} c}{\partial y^{2}}$

The appropriate boundary conditions are:

$\left.\begin{array}{rl}u_{w}=C x^{p}, & v=v_{w}, \quad \frac{\partial T}{\partial y}=-\frac{q_{w}}{\kappa}, C=C_{\infty}+b x \quad \text { at } y=0 \\ u_{w} \rightarrow 0, \quad T \rightarrow T_{\infty}, \quad C \rightarrow C_{\infty} \text { as } y \rightarrow \infty\end{array}\right\}$

\section{Similarity Analysis}

In order to obtain a similarity solution of the problem, we introduce a similarity parameter $\delta$ such that $\delta(x)$ is a length scale. Now introducing the following dimensionless variables (13)-(16):

$\eta=\frac{y}{\delta(x)}=\left(\frac{c^{2-n}}{\frac{\kappa}{\rho}}\right)^{\frac{1}{n+1}} x^{\frac{\{p(2-n)-1\}}{n+1} y}$

$\psi(x, y)=\left(\frac{c^{1-2 n}}{\kappa / \rho}\right)^{-1 /(n+1)} x^{\{p(2 n-1)+1\} /(n+1)} f(\eta)$

$\theta(\eta)=\frac{\left(T-T_{\infty}\right) R e_{x}^{1 /(n+1)}}{q_{w} x / \kappa}$

$\varphi(\eta)=\frac{c-c_{\infty}}{b x}$

where, $\psi$ the stream function, $\eta$ is the dimensionless distance normal to the sheet, $f$ is the dimensionless stream function, $\theta$ is the dimensionless fluid temperature and $\varphi$ is the dimensionless fluid concentration. 
Using the similarity analysis (13) to (16) in equations (9) to (11), we obtain the following non-linear equations:

$\left(\left|f^{\prime \prime}\right|^{n-1} f^{\prime \prime}\right)^{\prime}+\frac{p(2 n-1)+1}{(n+1)} f f^{\prime \prime}-p\left(f^{\prime}\right)^{2}-M f^{\prime}$

$+\lambda \theta=0$

$\frac{3 N+4}{3 N \operatorname{Pr}} \theta^{\prime \prime}+\frac{p(2 n-1)+1}{(n+1)} f \theta^{\prime}+\frac{p(2-n)-1}{(n+1)} f^{\prime} \theta+Q \theta+$

$\operatorname{Ec}\left(\left|f^{\prime \prime}\right|^{n-1} f^{\prime \prime}\right)^{2}=0$

$\frac{1}{S c} \varphi^{\prime \prime}+\frac{p(2 n-1)+1}{(n+1)} f \varphi^{\prime}-f^{\prime} \varphi=0$

The boundary conditions after the transformations become,

$$
\begin{aligned}
f^{\prime}=1, & \left.f=\frac{n+1}{p(2 n-1)+1} f_{w}, \quad \theta^{\prime}=-1, \quad \varphi=1 \text { at } \eta=\right\} 0 \\
f^{\prime} & \rightarrow 0, \quad \theta \rightarrow 0, \quad \varphi \rightarrow 0 \quad \text { as } \eta \rightarrow \infty
\end{aligned}
$$

where,

$M=\frac{\sigma B^{2} x}{\rho u_{w}}$ is the magnetic field parameter,

$f_{w}=-\frac{v_{w}}{u_{w}} R e_{x}^{\frac{1}{n+1}}$ is the suction parameter,

$\lambda=\frac{G r}{R e_{x}^{\frac{1}{n+1}}}=\frac{g \beta\left(q_{w} / \kappa\right) x^{2}}{u_{w}^{2}} R e_{x}^{\frac{-1}{n+1}}$ is the buoyancy parameter,

$R e_{x}=\frac{\rho u_{w}^{2-n} x^{n}}{K}$ is the local Reynolds number,

$\operatorname{Pr}=\frac{x u_{w}}{\alpha} R e_{x}^{\frac{-2}{n+1}}$ is the Prandtl number, $N=\frac{\kappa \kappa_{1}}{4 \sigma_{1} T_{\infty}^{3}}$ is the

Radiation parameter, $Q=\frac{Q_{0} x}{u_{w} \rho c_{p}}$ is the local heat source

parameter, $E c=\frac{\left(u_{w}^{n+1 / 2}\right)^{2}}{c_{p} \frac{q_{w}}{\kappa} x^{n}} R e_{x}^{\frac{n}{n+1}}$ is local Eckert number

and $S C=\frac{u_{w} x}{D_{m}} R e_{x}^{-\frac{2}{n+1}}$ is the local Schmidt number.

Here, we note that the magnetic field strength $B$ should be proportional to $x$ to the power $(p-1) / 2$ to eliminate the dependence of $\mathrm{M}$ on $\mathrm{x}$ i.e. $B=B_{0} x^{(p-1) / 2}$, where $B_{0}$ is a constant. The parameters of engineering interest for the present problem are skin friction coefficient $\left(C_{f}\right)$, local Nusselt Number $\left(N u_{x}\right)$ and local Sherwood number $\left(S h_{x}\right)$, which indicate physically wall shear stress, local heat transfer rate and local mass transfer rate respectively. The Skin friction coefficient $\left(C_{f}\right)$ is given by

$$
C_{f}=\frac{\tau_{w}}{\frac{1}{2} \rho u_{w}^{2}}
$$

or, $R e_{x}^{1 /(n+1)} C_{f}=2\left|f^{\prime \prime}(0)\right|^{n-1} f^{\prime \prime}(0)$

The local Nusselt number $\left(N u_{x}\right)$ is given by

$$
N u_{x}=\frac{x q_{w}}{h\left(T_{w}-T_{\infty}\right)}
$$

or, $N u_{x} R e_{x}^{-1 /(n+1)}=\frac{1}{\theta(0)}$

The local Sherwood number $(S h)$ is given by

or, $S h_{x} R e_{x}^{-1 /(n+1)}=-\varphi^{\prime}(0)$

Thus from equation (21)-(23), we see that the skin friction coefficient $C_{f}$, local Nusselt number $N u_{x}$ and Sherwood number $\left(S h_{x}\right)$ are proportional to $2\left|f^{\prime \prime}(0)\right|^{n-1} f^{\prime \prime}(0), \frac{1}{\theta(0)}$ and $-\varphi^{\prime}(0)$ respectively.

\section{Results and Discussion}

The set of equations (17)-(19) with boundary conditions (20) are nonlinear and coupled. It is difficult to solve them analytically. Hence we adopt a procedure to obtain the solution numerically. Here we use the standard initial value solver shooting method namely Nachsheim-Swigert shooting iteration technique [20] (guessing the missing value) together with sixth order Runge Kutta -Butcher initial value solver. Results from numerical computation showing the effects of various parameters are presented graphically as well as in tabular form.

The effects of suction on the velocity, temperature and concentration profiles have been shown in the Fig.2(a), Fig.2(b) and Fig.2(c) respectively. In Fig.2, we observe that the velocity, temperature and concentration profiles decrease with the increase of suction parameter $\left(f_{w}\right)$. For $f_{w}=0.5$, we notice that the velocity profiles increase near the surface and at a small distance from the surface of the sheet start to decrease and in that case we get a pick of the velocity field. This indicates that for a flow field of higher suction, the velocity of the fluid particle is low. For $f_{w}=2.4$, the pick of the curve is very small to indicates the fact that the velocity field become stable quickly (see Fig.2(a)) near the stretching sheet.

However, for the value of the suction parameter $\left(f_{w}\right)$, the temperature profiles in Fig.2(b) and the concentration profiles in Fig.2(c) start to decrease monotonically from the very beginning. The decrease in the temperature and concentration profiles also indicates that suction stabilizes the temperature and concentration boundary layers.

We see that in Fig.3(a), the velocity profiles increase with buoyancy parameter $(\lambda)$ up to around $\eta \leq 2.6$ but after that the velocity profiles shows a slight decreasing trend as $\eta$ increase further. Thus we get a cross flow here. However, 


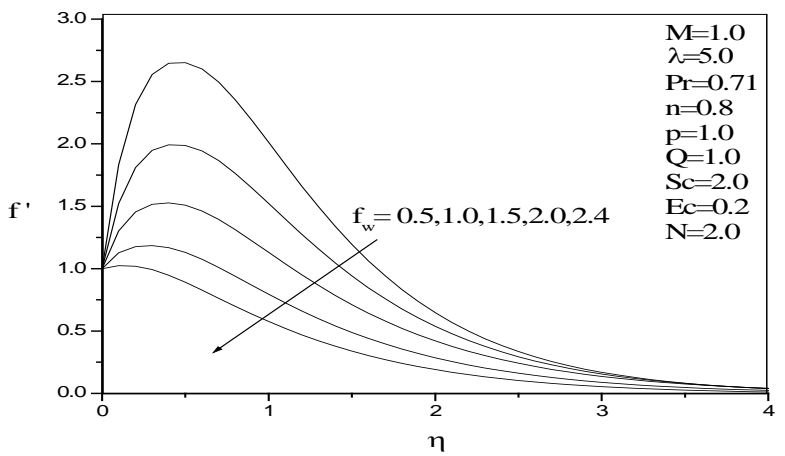

2(a)

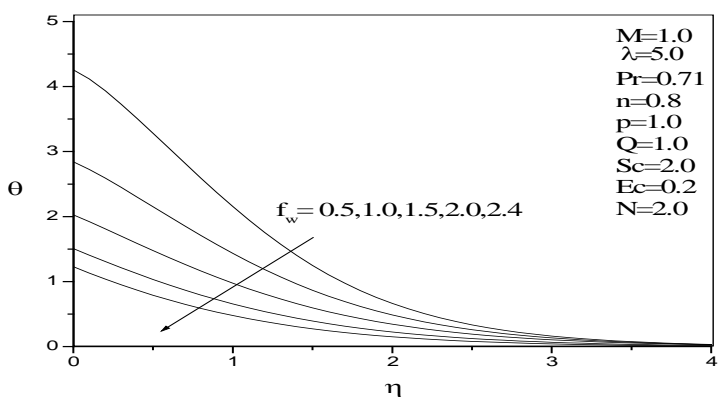

2(b)

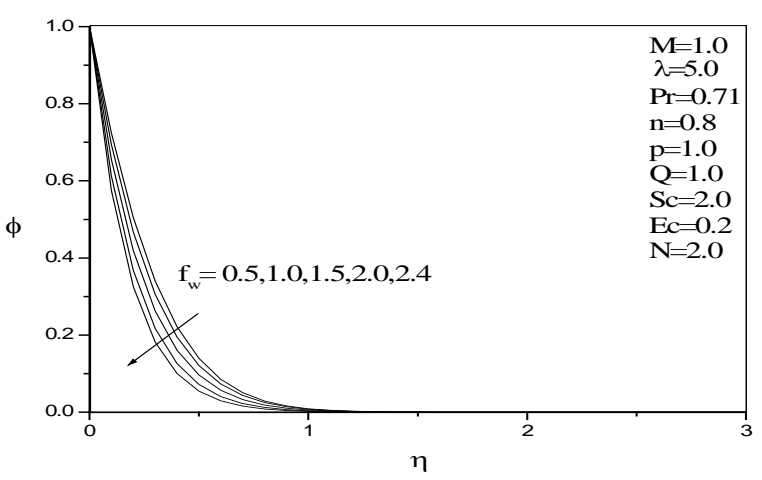

2(c)

Fig. 2. Effects of Suction parameter $\left(f_{w}\right)$ on (a) velocity (b) temperature and (c) Concentration profiles

near the surface the velocity profiles act quite differently for different values of $\lambda$. The velocity field increases slowly for $\lambda$ at first near the stretching sheet and then decreases monotonically. Fig.3(b) and Fig.3(c) exhibit that the temperature and the concentration profiles are strictly decreasing with the increase of buoyancy parameter $\lambda$. The case $\lambda=0$ corresponds to forced convection flow.

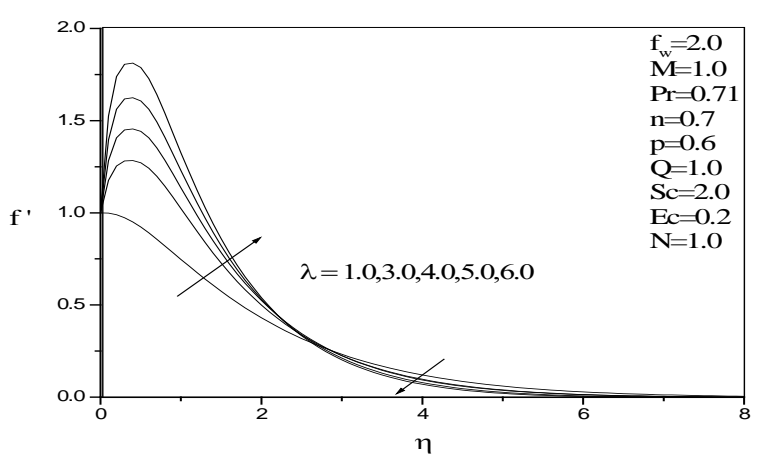

3(a)

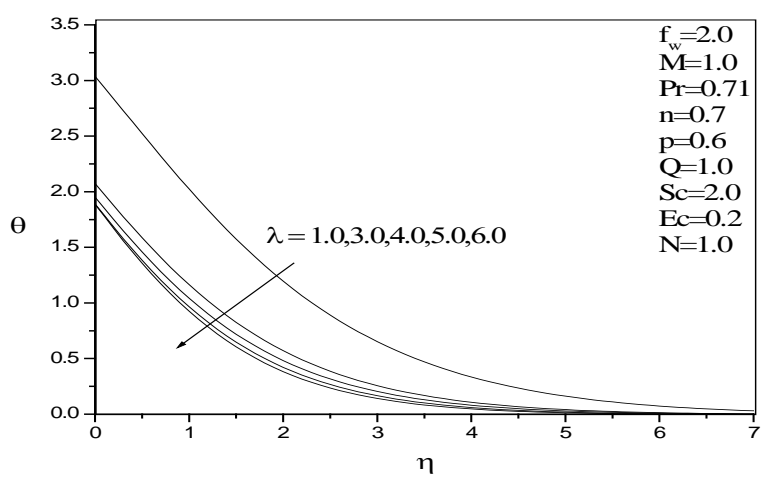

3(b)

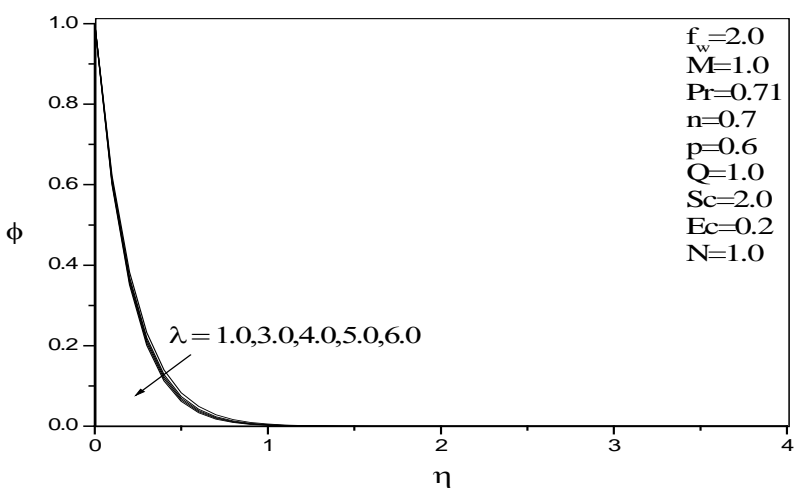

3(c)

Fig. 3. Effects of buoyancy parameter ( $\lambda$ ) on (a) velocity (b) temperature and (c) Concentration profiles 


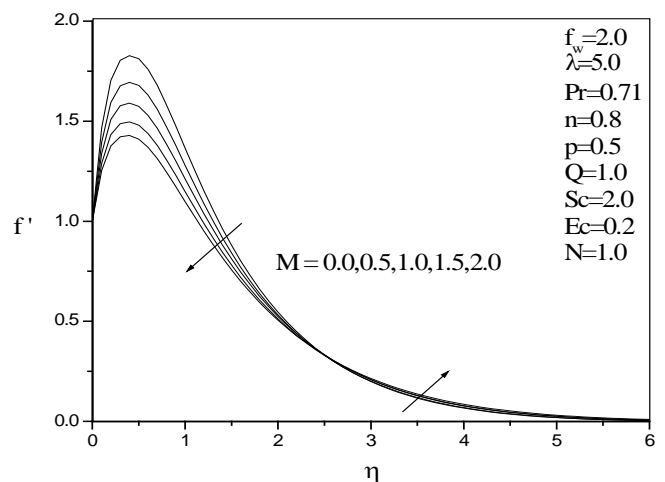

4(a)

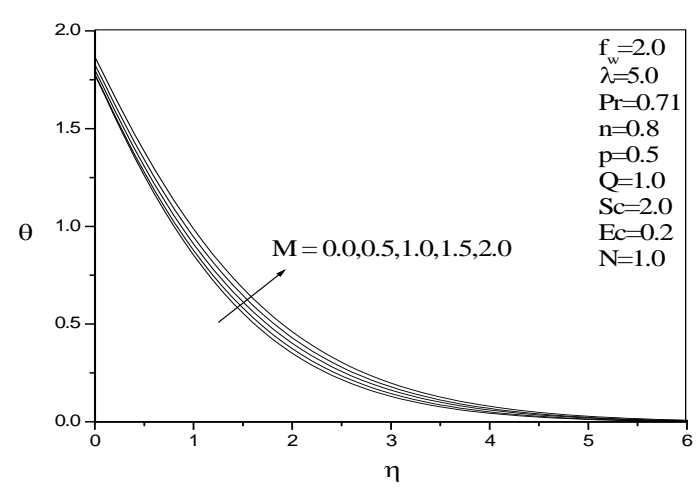

4(b)

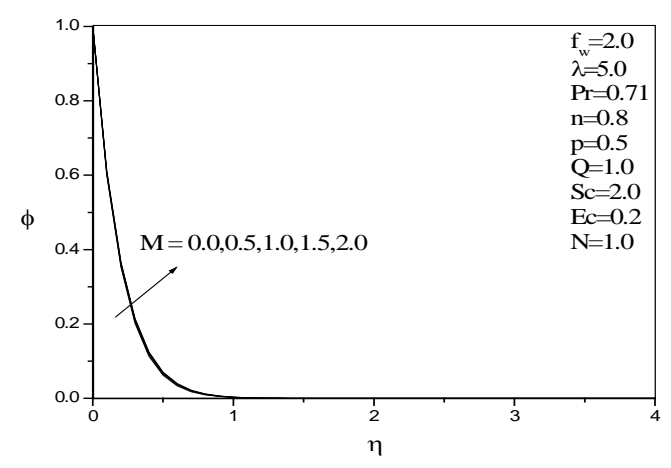

4(c)

Fig. 4. Effects of Magnetic field parameter $(M)$ on (a) velocity (b) temperature and (c) Concentration profiles

It is clear from Fig.4(a) that the velocity profiles decrease with magnetic parameter (M) up to around $\eta \leq 2.5$ but after that the velocity profiles shows a slight increasing trend as $\eta$ increase further. Thus we get a cross flow here. It clearly indicates that the transverse magnetic field opposes the transport phenomena and there is a sharp rise in velocity profiles near the surface, since the magnetic field lines acts as a string to retard the motion of the fluid. Fig.4(b) shows the heat transfer increase with the increase of the magnetic field strength for which the thermal boundary layer thickness decreases a small amount and in Fig.4(c) also show a smaller pattern of increasing mass transfer rate due to the magnetic field parameter $(\mathrm{M})$.
Fig.5(a) and Fig.5(b) show that the velocity and temperature profiles decrease with the increase of Prandtl number (Pr). However, from Fig.5(c) it is clear that the concentration profiles increase uniformly with the increase of Prandtl number (Pr). We observe that for $\operatorname{Pr}=0.71$, there is a pick in velocity boundary layers near the stretching sheet and for small $\mathrm{Pr}$ wall temperature is very high compared to larger values.

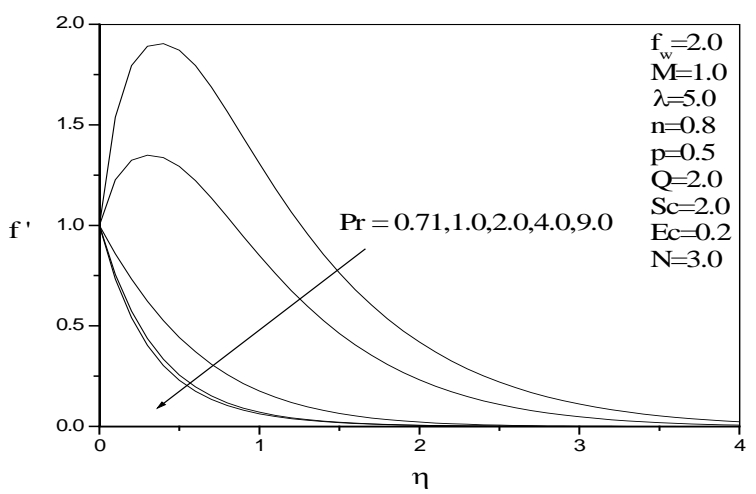

5(a)

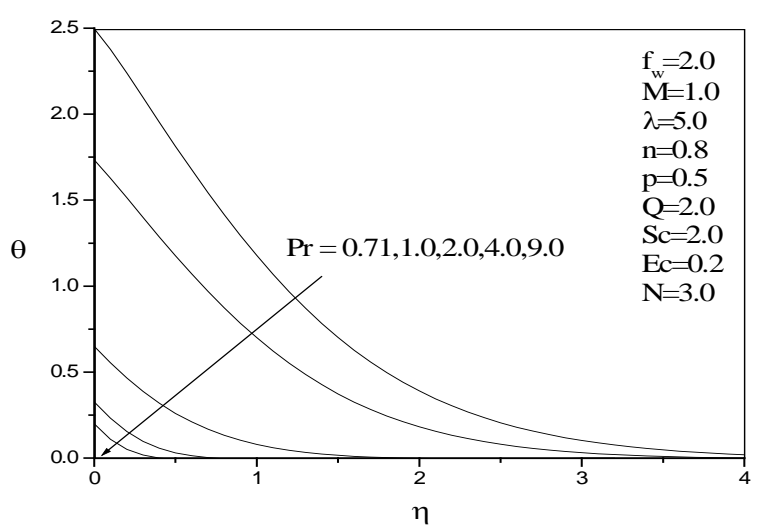

5(b)

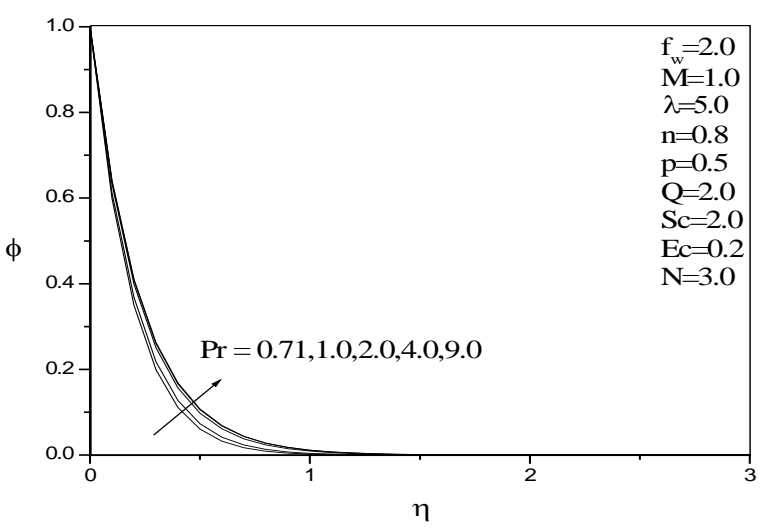

5(c)

Fig. 5. Effects of Prandtl number $(P r)$ on (a) velocity (b) temperature and (c) Concentration profiles 


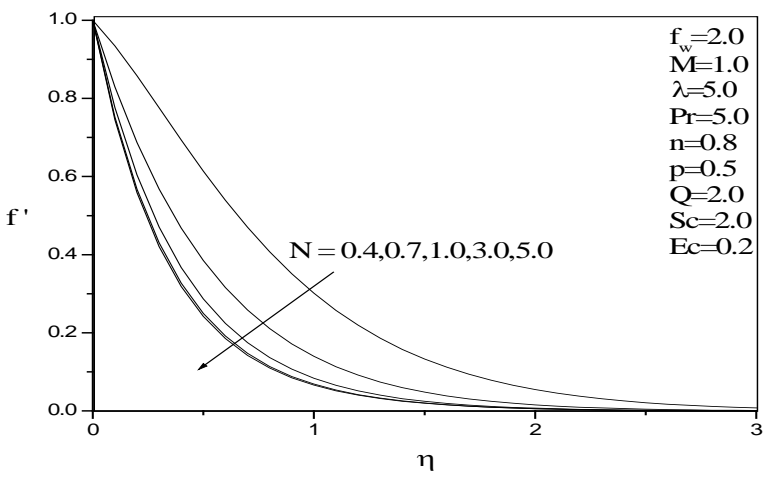

6(a)

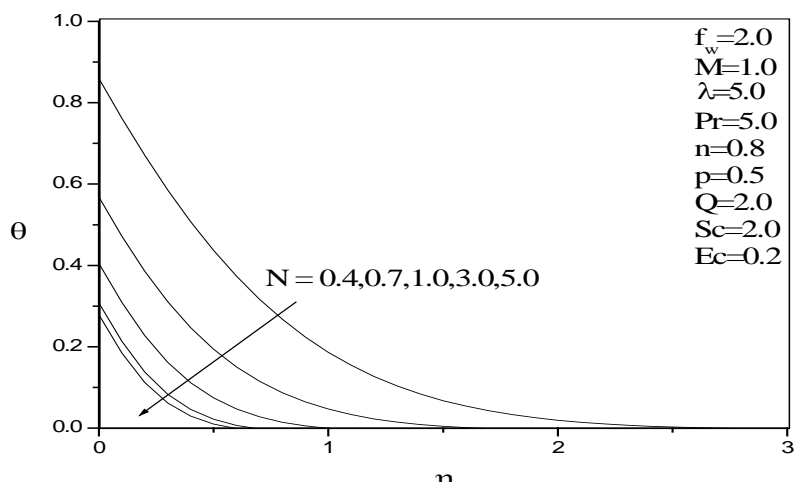

6(b)

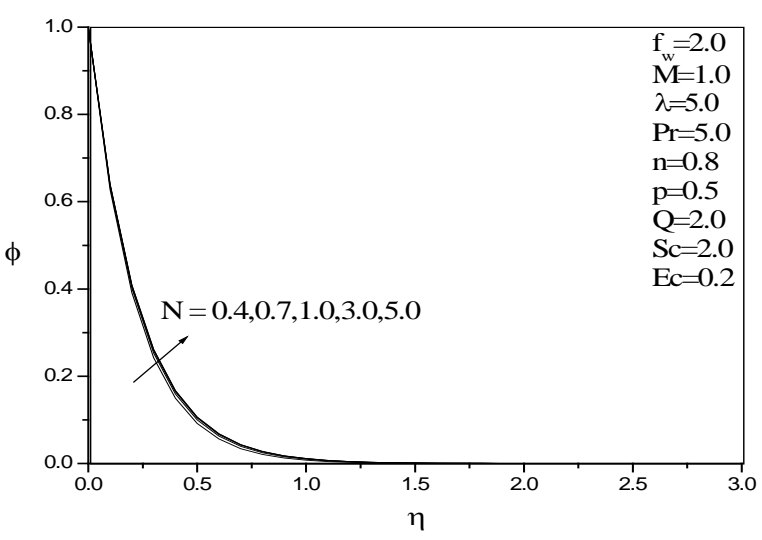

6(c)

Fig. 6. Effects of Radiation parameter $(N)$ on (a) velocity (b) temperature and (c) Concentration profiles

The effects of radiation parameter $(N)$ on velocity, temprature and concentration profiles are shown in Fig.6(a), Fig.6(b) and Fig.6(c) respectively. The velocity profiles rise near the surface for $N \leq 0.7$, since there exist a sharp decrease in the velocity and temperature profiles, so that can be used to control velocity and temperature boundary layers. The concentration profiles in Fig.6(c), with increase of radiation parameter $(\mathrm{N})$, the concentration in the vicinity of the boundary layer increases. Due to the radiation from a system, the wall temperature decreases to a great extent.
From Fig.6(b), we find that our experimental results agree with the Newton's law of cooling. So that the rate of heat transfer is thus increased.

It is observed from Fig. 7(a)-7(c) that the velocity and temperature profiles increase and concentration profiles decrease with the increase of heat source parameter (Q). Fig.7(c) explains the fact that the concentration profiles are decreasing with the increase of heat source parameter (Q) and that profiles shows a small variation.

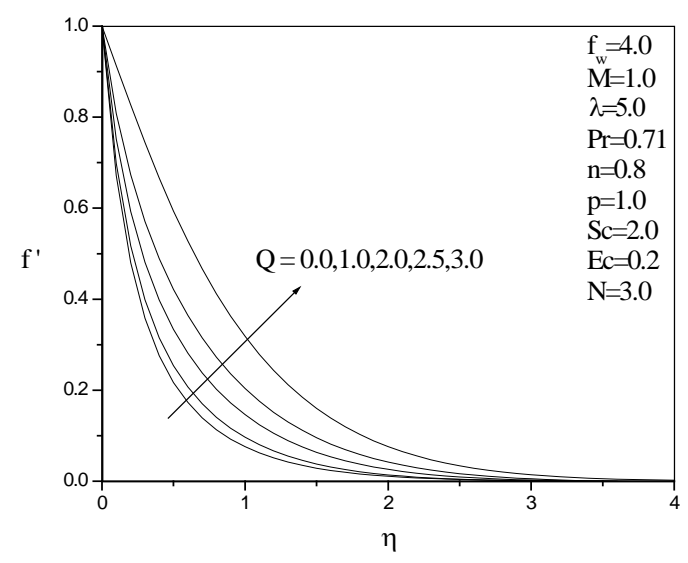

$7(a)$

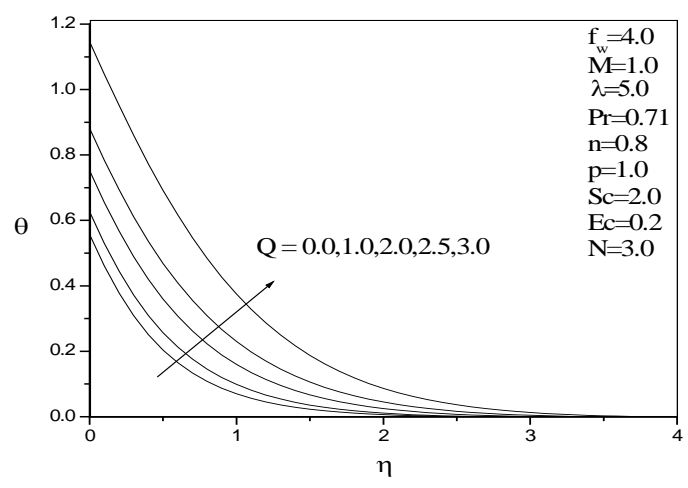

7(b)

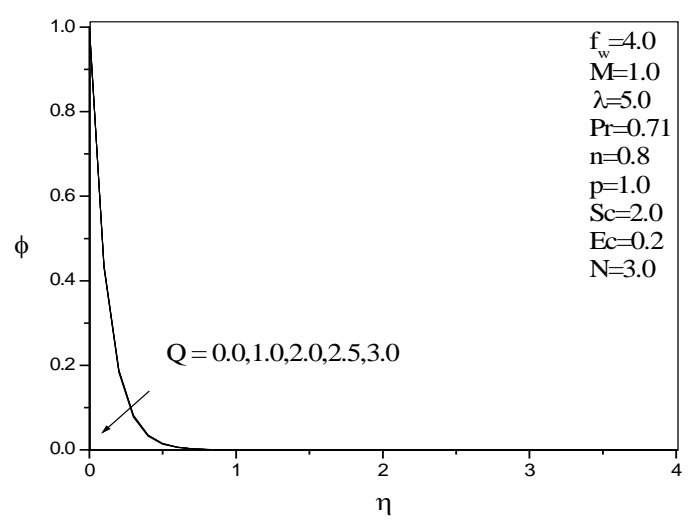

$7(\mathrm{c})$

Fig. 7. Effects of Heat source parameter $(Q)$ on (a) velocity (b) temperature and (c) Concentration profiles 
We observe from Fig.9, the velocity and temperature fields are increasing with the increase of the Eckert number (Ec) . The velocity and the temperature profiles show significant change for the increase of Eckert number (Ec). There is a notable difference in the temperature profiles. The thermal boundary layer thickness decreases with the increase of the Eckert number (Ec).

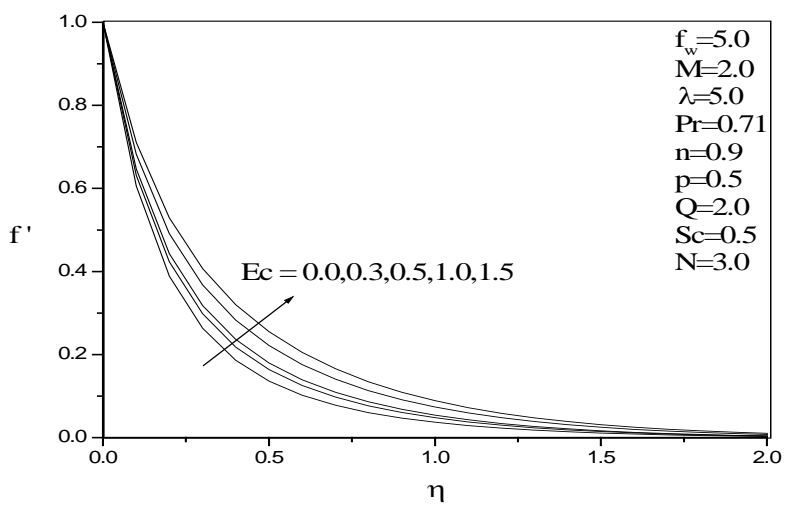

8(a)

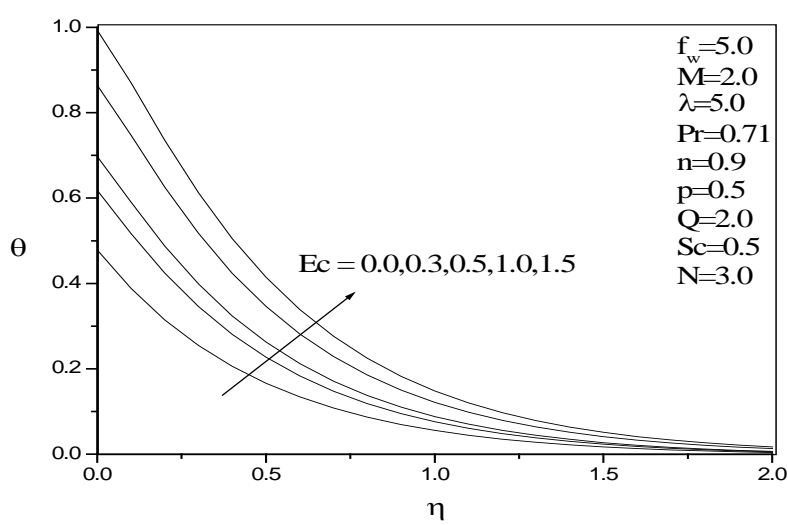

8(b)

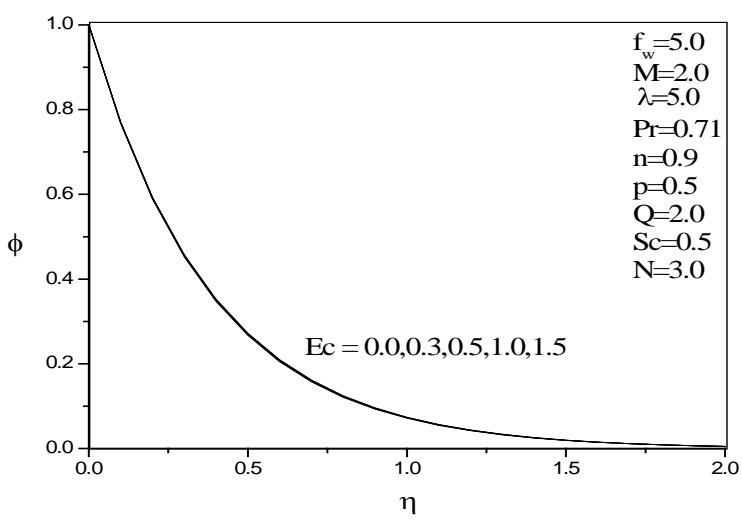

8(c)

Fig. 8. Effects of Eckert number $(E c)$ on (a) velocity (b) temperature and (c) Concentration profiles
On the otherhand in the Fig.9(c),we see that there is no change in the concentration profiles with the increase of Eckert number (Ec). So, we can say that Eckert number (Ec) has a significant effects on both velocity and temperature flow field but there is no effect on concentration field.

In Table 1, shows the comparison of the Skin friction Coefficient and local heat transfer Cofficient with $\mathrm{C}-\mathrm{H}$ Chen ${ }^{17}$ for various values of $n, M$ and $f_{w}$ making $\operatorname{Pr}=5$ and $p=0.5$ as fixed. C-H Chen ${ }^{17}$ analysed the system of transformed governing equation through using the centraldifference scheme with Newton iteration procedure for forced convection flow $(\lambda=0)$ in absence of thermal radiation and heat generation.

Table 1. Comparison of $C_{f} R e_{x}^{1 /(n+1)}$ and

$$
N u_{x} R e_{x}^{-\frac{1}{(n+1)}}
$$

\begin{tabular}{|c|c|c|c|c|c|c|}
\hline$n$ & $M$ & $f_{w}$ & $\begin{array}{l}C_{f} \operatorname{Re}_{x}^{1 /(n+1)} \\
\text { Present } \\
\text { study }\end{array}$ & $\begin{array}{l}\text { C-H Chen } \\
\text { [17] }\end{array}$ & $\begin{array}{l}N u_{x} R e_{x}-\frac{1}{(n+1)} \\
\text { Present } \\
\text { Study }\end{array}$ & $\begin{array}{l}\text { C-H Chen } \\
\text { [17] }\end{array}$ \\
\hline \multirow[t]{8}{*}{0.5} & \multirow[t]{3}{*}{0} & -0.2 & -1.6846680 & -1.680969 & 0.9749027 & 0.976082 \\
\hline & & 0.0 & -1.8371191 & -1.831551 & 1.5157894 & 1.517239 \\
\hline & & 0.6 & -2.4249666 & -2.408973 & 3.7730495 & 3.774795 \\
\hline & \multirow[t]{3}{*}{1} & -0.2 & -2.4723229 & -2.472213 & 0.7909711 & 0.791413 \\
\hline & & 0.0 & -2.6334386 & -2.633241 & 1.3454404 & 1.346116 \\
\hline & & 0.6 & -3.2137484 & -3.213067 & 3.6829965 & 3.683003 \\
\hline & \multirow{2}{*}{5} & 0.0 & -4.0467362 & -4.046795 & 0.9967436 & 0.996164 \\
\hline & & 0.6 & -4.6078741 & -4.608094 & 3.5274653 & 3.528467 \\
\hline \multirow[t]{8}{*}{1.0} & \multirow[t]{3}{*}{0} & -0.2 & -1.3461428 & -1.345021 & 1.1520367 & 1.152198 \\
\hline & & 0.0 & -1.5422799 & -1.540734 & 1.6939266 & 1.694009 \\
\hline & & 0.6 & -2.2741420 & -2.270891 & 3.9207932 & 3.920419 \\
\hline & \multirow[t]{3}{*}{1} & -0.2 & -2.3238054 & -2.323803 & 1.0187136 & 1.019734 \\
\hline & & 0.0 & -2.5193681 & -2.519363 & 1.5770303 & 1.578428 \\
\hline & & 0.6 & -3.1985827 & -3.198565 & 3.8664837 & 3.866662 \\
\hline & \multirow[t]{2}{*}{5} & 0.0 & -4.7262306 & -4.726210 & 1.3225043 & 1.320497 \\
\hline & & 0.6 & -5.3668243 & -5.366930 & 3.7514712 & 3.754876 \\
\hline \multirow[t]{7}{*}{1.5} & \multirow[t]{3}{*}{0} & -0.2 & -1.1647997 & -1.164834 & 1.2373398 & 1.237304 \\
\hline & & 0.0 & -1.3943322 & -1.394412 & 1.7801629 & 1.780041 \\
\hline & & 0.6 & -2.2283916 & -2.228454 & 3.9972606 & 3.996479 \\
\hline & \multirow[t]{3}{*}{1} & -0.2 & -2.1890996 & -2.189081 & 1.1286669 & 1.127959 \\
\hline & & 0.0 & -2.4121719 & -2.412287 & 1.6881848 & 1.689593 \\
\hline & & 0.6 & -3.1782831 & -3.178401 & 3.9591785 & 3.958697 \\
\hline & 5 & 0.6 & -5.7686477 & -5.768535 & 3.8749892 & 3.874307 \\
\hline \multirow[t]{5}{*}{1.9} & \multirow[t]{3}{*}{0} & -0.2 & -1.0730688 & -1.073300 & 1.2789639 & 1.278189 \\
\hline & & 0.0 & -1.3234449 & -1.323156 & 1.8227149 & 1.822353 \\
\hline & & 0.6 & -2.2138990 & -2.213542 & 4.0401121 & 4.036595 \\
\hline & \multirow[t]{2}{*}{1} & 0.0 & -2.3495496 & -2.349473 & 1.7465925 & 1.744168 \\
\hline & & 0.6 & -3.1716860 & -3.170979 & 4.0067807 & 4.005932 \\
\hline
\end{tabular}

Table 2 reveals the implication of the Skin friction coefficient, the local heat transfer coefficient and the mass transfer coefficient for various values of $n, M$ and $f_{w}$ and taking $\operatorname{Pr}=5, p=0.5, N=2.0, S c=2.0, E c=0.2, Q=$ 2.0 and $G r=1.0$ as fixed. 
Table 2. Effects of $n, M$ and $f_{w}$ on parameters $C_{f} R e_{x}{ }^{1 /(n+1)}, N u_{x} R e_{x}^{-\frac{1}{(n+1)}}$ and $S h R e_{x}{ }^{-\frac{1}{(n+1)}}$.

\begin{tabular}{|c|c|c|c|c|c|}
\hline$n$ & $M$ & $f_{w}$ & $C_{f} R e_{x}^{1 /(n+1)}$ & $N u_{x} R e_{x}^{-\frac{1}{(n+1)}}$ & $S h R e_{x}^{-\frac{1}{(n+1)}}$ \\
\hline \multirow[t]{3}{*}{0.8} & 2.0 & $\begin{array}{l}3.0 \\
4.0 \\
5.0\end{array}$ & $\begin{array}{l}-1.4052517 \\
-7.7401285 \\
-10.2141787\end{array}$ & $\begin{array}{l}0.2402154 \\
0.8727745 \\
1.3683725\end{array}$ & $\begin{array}{l}6.5178880 \\
8.2920665 \\
10.2222046\end{array}$ \\
\hline & 3.0 & $\begin{array}{l}3.0 \\
4.0 \\
5.0\end{array}$ & $\begin{array}{l}-1.5703910 \\
-8.1291256 \\
-10.5256374\end{array}$ & $\begin{array}{l}0.2060397 \\
0.8403401 \\
1.3563109\end{array}$ & $\begin{array}{l}6.5149480 \\
8.2857073 \\
10.2187499\end{array}$ \\
\hline & 5.0 & $\begin{array}{l}4.0 \\
5.0\end{array}$ & $\begin{array}{l}-8.8476821 \\
-11.0813014 \\
\end{array}$ & $\begin{array}{l}0.8070426 \\
1.3340351 \\
\end{array}$ & $\begin{array}{l}8.2741090 \\
10.2127982 \\
\end{array}$ \\
\hline \multirow[t]{3}{*}{1.0} & 2.0 & $\begin{array}{l}3.0 \\
4.0 \\
5.0\end{array}$ & $\begin{array}{l}-2.2240629 \\
-7.9541893 \\
-10.4185468\end{array}$ & $\begin{array}{l}0.2818387 \\
0.9055793 \\
1.3981371\end{array}$ & $\begin{array}{l}6.5230425 \\
8.3293951 \\
10.2600944\end{array}$ \\
\hline & 3.0 & $\begin{array}{l}3.0 \\
4.0 \\
5.0\end{array}$ & $\begin{array}{l}-2.4528895 \\
-8.4167316 \\
-10.7783224 \\
\end{array}$ & $\begin{array}{l}0.2434386 \\
0.8874340 \\
1.3872134\end{array}$ & $\begin{array}{l}6.5191114 \\
8.3235551 \\
10.2571438 \\
\end{array}$ \\
\hline & 5.0 & $\begin{array}{l}4.0 \\
5.0 \\
\end{array}$ & $\begin{array}{l}-9.2280032 \\
-11.4370118 \\
\end{array}$ & $\begin{array}{l}0.8579202 \\
1.3684419 \\
\end{array}$ & $\begin{array}{l}8.3137308 \\
10.2519059 \\
\end{array}$ \\
\hline \multirow[t]{3}{*}{1.2} & 2.0 & $\begin{array}{l}3.0 \\
4.0 \\
5.0\end{array}$ & $\begin{array}{l}-2.7347289 \\
-8.1472505 \\
-10.6060337\end{array}$ & $\begin{array}{l}0.3136849 \\
0.9292932 \\
1.4132001\end{array}$ & $\begin{array}{l}6.5327249 \\
8.3586993 \\
10.2892086\end{array}$ \\
\hline & 3.0 & $\begin{array}{l}3.0 \\
4.0 \\
5.0 \\
\end{array}$ & $\begin{array}{l}-3.0948490 \\
-8.6463027 \\
-11.0095747 \\
\end{array}$ & $\begin{array}{l}0.2767369 \\
0.9125569 \\
1.4033860 \\
\end{array}$ & $\begin{array}{l}6.5267373 \\
8.3537719 \\
10.2866572 \\
\end{array}$ \\
\hline & 5.0 & $\begin{array}{l}4.0 \\
5.0 \\
\end{array}$ & $\begin{array}{l}-9.5400608 \\
-11.7593451 \\
\end{array}$ & $\begin{array}{l}0.8850313 \\
1.3864239 \\
\end{array}$ & $\begin{array}{l}8.3453278 \\
10.2820587 \\
\end{array}$ \\
\hline 1.5 & $\begin{array}{l}2.0 \\
5.0\end{array}$ & $\begin{array}{l}3.0 \\
5.0\end{array}$ & $\begin{array}{l}-3.2049019 \\
-12.3055750\end{array}$ & $\begin{array}{l}0.346072 \\
1.3989173\end{array}$ & $\begin{array}{l}6.5573418 \\
10.3249649\end{array}$ \\
\hline
\end{tabular}

\section{Conclusions}

In this paper, an experiment is performed to study MHD free convection flow of a non-Newtonian power law fluid along a stretching sheet in presence of magnetic field with heat generation, thermal radiation and viscous dissipation. Analyzing the present study we can make the following conclusions:

1. Suction parameter $\left(f_{w}\right)$ has significant effect on the flow field. With the increasing of suction parameter, the velocity, temperature and concentration profiles are decreasing. So, suction stabilizes the boundary layer growth.

2. Buoyancy parameter $(\lambda)$ has significant effect on the flow field. Large values of buoyancy parameter can be used to control temperature and concentration boundary layers.

3. Prandtl number ( $\operatorname{Pr})$ has significant effects on the entire flow field.

4. Using Magnetic field parameter $(M)$ we can control the flow field and has a significant effect of heat and mass transfer.

5. Large values of heat source parameter $(Q)$ have significant effect on the velocity and temperature profiles whereas it causes small reduction in the concentration profiles.

6. For considering viscous dissipation, we observe that Eckert number $(E C)$ has significant effect on velocity and temperature profiles but no effect on concentration profiles.

7. Thermal radiation $(\mathrm{N})$ has significant effects on the velocity and temperature field. Due to radiation, the drag of the surface decreases but the heat transfer rate increases. Thus radiation can be used effectively to control the velocity and thermal boundary layer.

\section{Reference}

1. Sakiadis B. C., 1961. Boundary Layer behavior on continuous solid surfaces: I. The Boundary Layer Equations for Two Dimensional and Axisymmetric Flow, AICHE J. 7 , 26-28.

2. Schowalter W.R., 1960. The application of boundary-layer theory to power-law pseudo plastic fluid: Similar solutions, AICHE J. 6, 24-28.

3. Elbashbeshy E. M. A., 1998. Heat Transfer over a Stretching Surface with Variable Surface Heat Flux, J.Phys. D: Appl.Phys. 31, 1951-1954.

4. Andersson H.I., K.H Bech, B.S. Dandapat, 1992. Magneto hydrodynamic flow of a power-law fluid over a stretching sheet, Int J Non-Linear Mech 27, 929-936.

5. Cortell R., 2005. A note on magneto hydrodynamic flow of a power-law fluid over a stretching sheet, Appl Math Comput 168, 557-566.

6. Mahmoud M.A.A., M.A.E. Mahmoud, 2006. Analytical solutions of hydro magnetic boundary-layer flow of a non-Newtonian power-law fluid past a continuously moving surface, ActaMech 181, 83-89.

7. Singh B., C. Thakur, 2002. An exact solution of plane unsteady MHD non-Newtonian fluid flows, Indian Journal of pure and applied maths 33(7), 993-1001.

8. Chiam T.C., 1995. Hydro magnetic flow over a surface stretching with a power-law velocity,Int J EngSci 33, 429-435.

9. Kishan N., B.S. Reddy, 2012. Mhd Flow and Heat Transfer of a Non-Newtonian Power-Law Fluid Past a Stretching Sheet With Suction/Injection and Viscous Dissipation, IJMAR 1(4), 681-705.

10. Vajravelu K., A. Hadjinicolaou, 1997. Convecti- ve Heat Transfer in an Electrically Conducting Fluid at a Stretching Surface with Uniform Free Stream, Int. J. Eng. Sci., 35, 1237-1244.

11. Rajgopal K. R., T.Y. Na, A.S. Gupta, 1984 Flow of a Viscoelastic Fluid over a Stretching Sheet, Rhoel, Acta 23, 213-215.

12. Dandapat B.S., A.S. Gupta, 2005. Flow and Heat Transfer in a Viscoelastic Fluid over a Stretching Sheet, Int. J. Non-Linear Mech. 40 , 215-219.

13. Datti P.S., K.V. Prasad, M.S. Abel, A. Joshi, 2005. MHD Viscoelastic Fluid Over a Non-Isothermal Stretching Sheet, Int. J. Eng. Sci. 42, 935-946.

14. Samad M.A., M. Mohebujjaman, MHD 2009. Heat and Mass Transfer Free Convection Flow Along a Vertical Stretching Sheet in Presence of Magnetic Field With Heat Generation, Res. J. Appl. Sci. Eng. Technology, 1(3), 98-106.

15. Rahman M.M., M.A. Sattar, 2006. Magnetohydrodynamic Convective Flow of a Micropolar Fluid Past a Continuously Moving Vertical Porous Plate in the Presence of Heat Generation/Absorption, ASME J. Heat Transfer 128, 142-152.

16. Raptis A., 1998. Flow of a Micropolar Fluid Past a Continuously Moving Plate by the Presence of Radiation, Int. J. Heat Mass Transfer 41, 2865-2866.

17. Chen Chien-Hsin, 2008. Effects of magnetic field and suction/injection on convection heat transfer on non-Newtonian power-law fluids past a power-law stretched sheet with surface heat flux,Int J Thermal Sciences 47, 954-961.

18. Nachtsheim P.R., P. Swigert, 1965. Satisfaction of the asymptotic boundary conditions in numerical solution of the system of nonlinear equations of boundary layer type, NASA TNDMemorandum, No. $\mathbf{3 0 0 4}$.

19. Khaleque Tania S., M.A. Samad, 2010. Effects of Radiation, Heat Generation and Viscous Dissipation on MHD Free Convection Flow Along a Stretching Sheet, Res. J. Appl. Sci. Eng. Technology, 2(4) , 368-377. 
